\title{
ANÁLISE DE DISCURSOS NO ENSINO DE CIÊNCIAS: CONSIDERAC̄̃̃ES TEÓRICAS, IMPLICAC̣ÕES EPISTEMOLÓGICAS E METODOLÓGICAS
}

\author{
Aroaldo Veneu * \\ Gleice Ferraz ** \\ Flavia Rezende ***
}

RESUMO: Como parte da tendência predominantemente qualitativa da produção acadêmica na área de ensino de Ciências, observase também o crescimento da apropriação de abordagens teóricas e metodológicas para a análise de discursos. Diante desse panorama, pretendemos contribuir para o aprofundamento dessas apropriações, estabelecendo, do ponto de vista teórico, alguns diálogos e contrapontos entre a abordagem utilizada com maior frequência nos trabalhos investigados - a filosofia da linguagem de Bakhtin - e as outras duas vertentes mais frequentes: a análise de conteúdo e a análise do discurso de linha francesa. Do ponto de vista metodológico, nossa contribuição se dá pela apresentação de um dispositivo analítico elaborado com base na teoria bakhtiniana. PALAVRAS-CHAVE: Análise de discurso. Análise bakhtiniana. Dispositivo analítico. Ensino de Ciências.

\section{ANÁLISIS DEL DISCURSO EN LA ENSEÑANZA DE CIENCIAS: CONSIDERACIONES TEORICAS, IMPLICACIONES EPISTEMOLÓGICAS Y METODOLÓGICAS \\ RESUMEN: Como parte de la tendencia predominantemente cualitativa de la producción académica en el campode la enseñanza de Ciencias, se observa también el crecimiento de la apropiación de abordajes teóricos y metodológicos para el análisis de discursos. Frente a ese panorama, pretendemos contribuir para la profundización de estas apropiaciones, estableciendo, del punto de vista teórico, algunos diálogos y contrapuntos entre el abordaje utilizado con mayor frecuencia en los trabajos investigados - la filosofía del lenguaje de Bakhtin - y las otras dos vertientes más frecuentes: el análisis de contenido y el análisis del discurso de línea francesa. Del punto de vista metodológico, nuestra contribución se da por la presentación de un dispositivo analítico elaborado con base en la teoría bakhtiniana.}

PALABRAS CLAVE: Análisis del discurso. Análisis bakhtiniana. Dispositivo analítico. Enseñanza de ciencias.

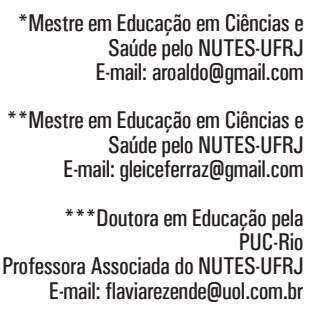


DISCOURSE ANALYSIS IN SCIENCE EDUCATION: THEORETICAL CONSIDERATIONS, EPISTEMOLOGICAL AND METHODOLOGICAL IMPLICATIONS

ABSTRACT: As part of the predominantly qualitative trend of research in science education, appropriation of approaches to linguistic data analysis has also recently increased. Considering this situation, we intend to contribute to the deepening of the appropriation of linguistic data analysis discussing from a theoretical point of view, concepts and epistemological aspects of the most frequent approaches, seeking to compare some fundamentals and conceptions of language associated with Bakhtin's philosophy of language with the content analysis and with discourse analysis. From a methodological standpoint, our contribution is given by the presentation of an analytical device elaborated in the basis of Bakhtinian theory.

KEYWORDS: Discourse analysis. Bakhtinian analysis. Analytical device. Science teaching. 


\section{INTRODUÇÃO}

Como parte da tendência predominantemente qualitativa da produção acadêmica na área de ensino de Ciências nos úlimos anos, observa-se também o crescimento da apropriação de abordagens teóricas e metodológicas para a análise de discursos. Chamamos atenção para o fato de que a palavra "discurso", nesta altura no trabalho, não implica filiação a nenhuma concepção particular de linguagem e se refere a qualquer texto, produzido oralmente ou por escrito, como respostas de professores ou alunos a questionários e entrevistas, documentos oficiais, livros didáticos etc. Mais adiante, quando formos aprofundar as questões epistemológicas e nos comprometer com a concepção de linguagem que norteia a segunda parte do trabalho, retomaremos a importantíssima questão da relação entre o referencial teórico-metodológico usado para a análise, suas características e denominação.

Também é importante destacar que o presente trabalho é um ensaio teórico, que pretende estabelecer diálogos e contrapontos entre os autores que têm sido utilizados com mais frequência para fazer a análise de discursos na área de Ensino de Ciências. Assim, o levantamento abaixo não pretende ser uma revisão de literatura, mas uma identificação quantitativa dos autores e das abordagens mais utilizadas para o tratamento do tema na produção da área.

A busca da palavra "discurso" no título ou no corpo dos artigos publicados nos últimos cinco anos nos periódicos Qualis A da área de ensino de Ciências retornou 49\% dos 93 artigos publicados em 2008, 57\% dos 101 artigos publicados em 2009, 58\% dos 122 artigos publicados em 2010 e 72\% dos 123 artigos publicados em 2011.

A leitura desses artigos permitiu dividi-los em dois grandes grupos. No primeiro grupo, classificamos os 198 trabalhos em que a palavra "discurso" é usada de maneira periférica, mesmo que uma única vez, como nas expressões "o discurso da mídia" ou "o discurso da ciência". No outro grupo, classificamos os 66 artigos em que a palavra "discurso" é usada de forma central, qualificado como um objeto de pesquisa, incluindo: falas de professores, alunos, textos de livros didáticos, textos de políticas públicas, etc. No entanto, ao contrário do que poderíamos esperar, a qualificação do objeto como discurso nem sempre implica uma filiação a alguma concepção de análise do discurso e de linguagem: 42\% dos artigos ou não fazem qualquer alusão a um referencial teórico da área de linguagem ou, quando fazem, não detalham ou indicam que parte das teorias citadas embasará a concepção de análise e de linguagem do artigo.

Entre os 52 artigos que explicitam referenciais teóricos sobre discurso, encontramos uma diversidade de teorias até mesmo divergentes no que diz respeito à concepção de linguagem, suas relações com o sujeito e o contexto, etc., indo de Lacan a Vygotsky, de Toulmin a Foucault, passando por Bronckart, Charaudeau e Peirce, num total de 20 autores. Mas foi possível identificar um núcleo que compreende três autores: Bakhtin (citado 18 vezes), Orlandi, identificada com a 
análise do discurso de linha francesa (citada 12 vezes), e Bardin, identificada com a análise de conteúdo (citada seis vezes). Os demais foram citados, no máximo, três vezes cada. No entanto, em nenhum dos 52 trabalhos pesquisados, nem mesmo nos 38 que citam e detalham suas concepções de linguagem, os autores problematizam o texto que resulta do seu trabalho de pesquisa a partir das questões epistemológicas que decorrem das relações entre o texto, o contexto, o sujeito e o sentido estabelecidas pelo referencial teórico que adotaram. É importante destacar que a lacuna que identificamos não está relacionada à metarreflexão, apontando limitações da proposta analítica, diálogos dos resultados com a literatura, relevância dos resultados, mas à falta de problematização das implicações epistemológicas do referencial linguístico para o próprio trabalho de pesquisa produzido.

O amplo quadro que descrevemos anteriormente obviamente deixou de fora vários trabalhos, seja por serem importantes publicações sobre esse tema anteriores a 2008, ou publicações em revistas internacionais ou em outros veículos, como livros, capítulos de livros, teses e dissertações. Dentro desse grupo estão trabalhos precursores da utilização dos referenciais de análise do discurso na pesquisa em ensino de Ciências, como, por exemplo, os trabalhos de Mortimer e Scott (2002), Almeida (2004) e Martins (2007), que vêm, desde então, dando uma contribuição fundamental para essa área, no âmbito da análise do discursoem diferentes vertentes.

Mesmo que essas iniciativas representem um avanço significativo, lacunas metodológicas e epistemológicas que percebemos no levantamento descrito anteriormente dão ideia do quanto ainda precisamos avançar. $\mathrm{O}$ presente trabalho dialoga mais de perto com esses resultados e encontra sua principal motivação na possibilidade de contribuir para o necessário aprofundamento e aprimoramento da utilização de análise de discursos na área de ensino de Ciências.Para tal, procuramos explicitar e comparar alguns fundamentos epistemológicos e a concepção de linguagem associados à filosofia da linguagem de Bakhtin e seu círculo (1976, 2003a, 2003b, 2003c, 2006) com a análise de conteúdo e com a análise do discurso de linha francesa. Dessa forma, pretendemos explicitar algumas das diferenças que julgamos radicais entre suas concepções epistemológicas e linguísticas. Do ponto de vista metodológico, nossa contribuição se dá pela apresentação de um dispositivo analítico baseadoestritamente na teoria bakhtiniana. Pretendemos, assim, oferecer subsídios teóricos e metodológicos para fomentar a discussão sobre consequências e desdobramentos epistemológicos relativos à escolha de diferentes referenciais teóricos sobre linguagem para a pesquisa em ensino de Ciências.

\section{POR UMA ANÁLISE BAKHTINIANA}

Chamaremos de análise bakhtiniana uma análise de textos com base na concepção de linguagem elaborada pelo pensador russo Mikhail Bakhtin (1895-1975) e pelos intelectuais que, ao longo das décadas de 1920 e 1930, estiveram ao seu redor, comumente chamados de "o círculo de Bakhtin". 
Bakhtin (2006) apresenta sua concepção de linguagem a partir de críticas a duas das principais linhas de pensamento linguístico de seu tempo: o "objetivismo abstrato", que considera a fala como uma simples materialização do sistema abstrato da língua, associado a Saussure e seus seguidores, e o "subjetivismo individualista”, que considera a linguagem como uma forma de expressão individual e completamente livre, proposta por Vossler e seus discípulos.

Dentre os signos, Bakhtin (2006) aponta a palavra como signo ideológico por excelência, afirmando que ela não seria fruto da livre expressão de um pensamento interior, mas seria sempre escolhida tanto em função da pessoa do interlocutor imediato quanto de um auditório social mais abrangente. Durante o processo de interação verbal, o uso da mesma língua pelas várias classes sociais terminaria fazendo com que o signo bakhtiniano tivesse uma natureza inarredavelmente ideológica e valorativa: "o signo se torna a arena onde se desenvolve a luta de classes” (BAKHTIN, 2006, p.46) - diferentemente do signo linguístico saussureano, de natureza neutra.

Bakhtin (2003a) propõe também um entendimento mais amplo do conceito de texto, considerado como qualquer conjunto coerente de signos, seja ele escrito ou oral e propõe ainda uma diferenciação entre texto e enunciado. Para Bakhtin (2003b, 2003c, 2006), o enunciado seria a verdadeira unidade de comunicação verbal que deve levar em consideração não só a palavra em si, mas o seu autor e todo o contexto social, histórico e cultural em que estão inseridos; ao passo que o texto são aquelas palavras que retiramos do dicionário sem qualquer contexto e/ou ligação com aquele que as profere.

Sendo assim, Bakhtin (2003a, 2003b, 2003c, 2006) insiste que a análise dos enunciados seja feita nas condições concretas em que se realiza, ao contrário de uma análise textual. Noutro ensaio vai além, afirmando que "o enunciado concreto [...] nasce, vive e morre no processo da interação social entre os participantes da enunciação[...]. Quando cortamos o enunciado do solo real que o nutre, perdemos a chave tanto de sua forma quanto de seu conteúdo" (VOLOSHINOV e BAKHTIN, 1976, p. 9-10). É muito importante ressaltar aqui que essas condições concretas a que o autor se refere incluem, mas não se restringem às condições imediatas, instantâneas, de um tête-à-tête, tanto do ponto de vista da interlocução quanto do ponto de vista da escala de tempo e do contexto. No enunciado bakhtiniano estão imbricadas três escalas de tempo, interlocução e contexto: a primeira, mais imediata, é a do interlocutor imediato, do contexto imediato e do tempo instantâneo - correspondendo, sim, a um tête-à-tête; a segunda é a do grupo social, do contexto social e do tempo histórico. Já a terceira é a de um supradestinatário , de um contexto social e cultural mais amplo e do grande tempo.

Outra propriedade dos enunciados extremamente relevante para o estabelecimento de uma análise bakhtiniana é o fato de que são dialógicos, concepção fundamental da teoria bakhtiniana. Assim, não são autossuficientes, não existem de forma estanque e isolada, mas formando uma espécie de rede em que "uns conhecem os outros e se refletem mutuamente uns nos outros. [...] Cada enuncia- 
do é pleno de ecos e ressonâncias de outros enunciados [...] os rejeita, confirma, completa, baseia-se neles, subentende-os com conhecidos, de certo modo os leva em conta" (BAKHTIN, 2003c, p. 297).

Assim, os enunciados, por se constituírem de signos/palavras ideológicas e valorativas, são, igual e inarredavelmente, ideológicos e valorativos. Estão articulados numa rede em que se tocam, se conhecem e se rejeitam e respondem. Incorporam, ainda, marcas das três escalas de tempo, interlocução e contexto. Entendemos, por isso, que não há a mais remota maneira de considerá-los neutros.

$\mathrm{E}$, se levarmos em consideração o fato de que a análise de um enunciado terá como resultado um outro enunciado - que, assim como o enunciado analisado, será ideológico, valorativo, estará articulado com a cadeia de enunciados, com as três escalas de tempo interlocução e contexto -, veremos que, para Bakhtin, o conhecimento de um objeto não neutro se faz por intermédio de um objeto de natureza idêntica - e não neutra. Essa concepção é essencial para assumir um posicionamento epistemológico.

A dimensão valorativa do enunciado, elaborada a partir de elementos lexicais, gramaticais, retóricos, destaque/apagamento de outros textos, etc., materializa um posicionamento axiológico do autor em relação ao objeto de sua fala, criando, para o leitor, uma espécie de imagem que faz do autor, que, para Bakhtin, nunca coincide com o autor propriamente dito. A ideia é que em qualquer obra de arte é possível perceber, sentir e compreender o autor, apesar de nunca o vermos nas imagens representadas. Assim, Bakhtin faz a distinção entre "autor criador"aquele que diz "eu" no texto- e "autor pessoa" - a pessoa de carne e osso que escreve.

O mesmo ocorreria no polo da recepção, em que, por motivos análogos, haveria alteridade entre a imagem que o autor faz do destinatário - "destinatário suposto" - e o destinatário propriamente dito.

Reforça a problematização que pretendemos realizar com este trabalho a distinção que Bakhtin faz entre o objeto das ciências naturais e o das ciências humanas. Primeiramente, propõe que conhecimento de ambas as ciências é mediado pelos signos - e, particularmente pelas palavras, entendidas como reflexos subjetivos de mundo objetivo, de uma consciência que reflete algo. Isso já daria à subjetividade um papel central na epistemologia bakhtiniana. No entanto, há mais: enquanto as ciências naturais teriam por interesse principal as coisas, um objeto apenas falado, as ciências humanas teriam por interesse principal o homem, um objeto que seria simultaneamente falado e falante. Assim, enquanto o processo de conhecimento de um objeto exclusivamente falado seria marcado por uma consciência - a da pessoa que o conhece -, o processo de conhecimento de um objeto falado e falante seria marcado pelo encontro de duas consciências: a do sujeito que conhece e a do sujeito que é conhecido. A subjetividade, assim, seria constitutiva do enunciado bakhtiniano tanto no caso do conhecimento de coisas e, mais ainda, no caso do conhecimento de pessoas - com impactos igualmente importantes para o argumento que ora desenvolvemos. 


\section{POR QUE A ANÁLISE DE CONTEÚDO SE AFASTA DA ANÁLISE BAKHTINIANA?}

A análise de conteúdo teve sua origem nas pesquisas iniciadas por $\mathrm{H}$. Lasswell, em 1915, que culminaram com a publicação do livro Propaganda Technique in the World War, em 1927. Fortemente alinhada a uma concepção positivista de ciência, seus principais objetos de estudo eram, à época, textos de imprensa e de propaganda (ROCHA e DEUSDARÁ, 2006; BARDIN, 1995) com o objetivo de encontrar mensagens de jornais que possuíssem ideias de teor subversivo, como textos com ideologias nazistas, ou comunistas. Apoiada pela ascensão de um behaviorismo que serviu de reforço para o realce das relações entre o ser humano e suas expressões linguísticas, foi emergindo uma ferramenta poderosa que trazia a promessa de tornar transparente um sentido oculto.

Assim, entendemos que a análise de conteúdo parte da pressuposição de que em toda mensagem há uma significação ou conjunto de significações absolutas e invariáveis que, por estarem ocultos, não são captados em uma leitura superficial, mas sim a partir da análise, com os dados em mãos, procurando-se causas ou efeitos dos enunciados, para descobrir por que ou para quê certos aspectos foram concebidos (BARDIN, 1995). Nesse processo, de acordo com Rocha e Deusdará (2006, p. 38), "apreocupação com o rigor metodológico emerge sempre como instrumento de manutenção da neutralidade científica, garantia de que, ao preparar o texto, o pesquisador não estaria imprimindo nele compreensões subjetivas”.

Entendemos que as diferenças entre a análise de conteúdo e a análise bakhtiniana são radicais, justamente por terem suas raízes em questões epistemológicas. A partir do que apresentamos na seção anterior, é possível perceber que, do ponto de vista bakhtiniano, tanto o enunciado do sujeito pesquisado quanto o enunciado do pesquisador acerca da fala desse sujeito são igualmente ideológicos, valorativos, estão articulados ao contexto social, histórico, ao interlocutor (mediados por várias alteridades), etc. Entendemos, portanto, que não há a menor chance de que sejam neutros.

Acresce que o objeto das ciências humanas seria um objeto falante e falado, diferentemente do objeto das ciências exatas, que seria apenas um objeto falado. Feita no início da década de 1960, a observação feita por Bakhtin quanto ao desconhecimento desta diferença ainda é atual:

\footnotetext{
"O complexo acontecimento do encontro e da interação com a palavra do outro tem sido quase totalmente ignorado pelas respectivas ciências humanas (e, acima de tudo, pelos estudos literários). As ciências do espírito; seu objeto não é um mas dois espíritos (o que é estudado e o que estuda, que não devem fundir-se em um só espírito). O verdadeiro objeto é a inter-relação e a interação dos espíritos." (BAKHTIN, 2003a, p. 380)
}

É importante destacar, aqui, que a última sentença diz respeito à ontologia do texto: ele é a materialização do encontro entre duas consciências. Assim, a leitura da fala de um professor será o encontro entre as consciências desse professor e daquele que lê a sua fala. Desse modo, fica evidente que vários leitores do mesmo 
enunciado poderão chegar a resultados distintos, visto que cada um fará sua interferência na rede de significados de forma diferente. No âmbito da pesquisa, pode-se buscar a construção de consensos a partir da discussão dos pontos de vista de todos os envolvidos. De qualquer modo, o sentido, nesse caso, seria da ordem da "coisa para si".

Já a análise de conteúdo promete a revelação de um sentido verdadeiro, imanente e escondido no texto, e que pode ser desvendado mediante o uso de determinadas técnicas. Decorre disso que vários analistas de conteúdo, dotados do mesmo método, deverão encontrar sentidos muito parecidos - senão idênticos - para a análise de um mesmo texto ou conjunto de textos: se houver sentidos muito divergentes, ou um está certo e os demais errados, ou todos estão errados. De fato, Bardin (1995) indica que uma boa análise deve suscitar a homogeneidade, a pertinência, a objetividade, a fidedignidade e a produtividade.

Assim, entendemos que a análise de conteúdo seria "um trabalho de interpretação, mas que se pretende validar cientificamente pelo recurso às técnicas de quantificação que legitimarão a leitura de um texto" (ROCHA e DEUSDARÁ, 2006, p. 43) -, o que está completamente de acordo com a concepção positivista de ciência a que a análise de conteúdo se filiou quando do seu surgimento. O processo de encontrar o sentido escondido em um texto seria da mesma natureza do processo de medição de uma corrente elétrica: conhecendo o método científico e dispondo de instrumentos adequados e calibrados, um analista poderia evitar pistas falsas e resgatar o verdadeiro sentido do texto. O sentido na análise de conteúdo seria da ordem de uma "coisa em si", enquanto o texto, "coisificado" e não falante, se assemelharia ao objeto das ciências naturais - e não das humanas e sociais. Já a subjetividade - que, na análise bakhtiniana, é constitutiva do enunciado - gera, na análise de conteúdo, marcas indesejáveis e que devem ser evitadas e removidas via rigor metodológico. É importante destacar que essa subjetividade aqui tratada não se refere àquela subjetividade individualista a qual Bakhtin critica, onde qualquer sentido é válido. O sujeito em Bakhtin é dialógico e dialoga não apenas com seu contexo extraverbal, tanto imediato como mais amplo, mas também com a palavra do outro, com seu destinatário suposto. O enunciado é então constituído tanto pelo outro quanto pelo próprio falante que se apropria do enunciado do outro dando-lhe acabamento e textualidades próprios dentro de uma situação de comunicação concreta. Assim, segundo a teoria bakhtiniana, o sujeito apesar de não ser o "criador" do enunciado de maneira isolada, também não é completamente submisso à estrutura - história, ideologia, língua - ou à forma da língua, chamado, assim, de sujeito social.

\section{UMA ANÁLISE BAKHTINIANA É UMA ANÁLISE DO DISCURSO?}

Gill (2002) afirma haver pelo menos 57 modalidades distintas de análise do discurso, no entanto, na presente seção, não estabeleceremos aproximações e 
afastamentos epistemológicos entre essas diferentes modalidades. Iremos nos restringir a comparar aspectos que julgamos centrais entre o pensamento de Bakhtin, o de Pêcheux, reconhecido como um dos fundadores da análise do discurso de linha francesa, e o de Ducrot, que retoma os conceitos de enunciado e polifonia, centrais para o arcabouço bakhtiniano.

Um ponto importante de aproximação entre Bakhtin e Pêcheux é o fato de terem procurado, cada um em sua época e contexto, estabelecer relações entre linguagem, ideologia e sujeito. No entanto, a forma e a natureza que cada autor estabeleceu para essas relações são muito diferentes - e são um ponto de afastamento entre os teóricos.

Para Bakhtin (2003a), a ideologia se articularia com a linguagem por intermédio do signo, pois “[...] tudo que é ideológico possui um significado e remete a algo situado fora de si mesmo, [...] tudo que é ideológico é signo. Sem signos não existe ideologia” (BAKHTIN, 2003a, p. 31). A valoração desse signo decorreria justamente do fato de ele ser mobilizado por diferentes classes sociais e que a partir desse uso por diferentes classes surgiria o que o autor chama de índices de valor do signo, pois “em todo signo ideológico confrontam-se índices de valor contraditórios".

Já para Pêcheux (1997), não haveria a correspondência mútua entre o domínio dos signos e o domínio ideológico proposta por Bakhtin. O discurso materializaria o ideológico, mas não se confundiria com ele nem se reduziria ao signo. O autor retoma duas teses de Althusser - a de que só há prática através de e sob uma ideologia e a de que só há ideologia pelo sujeito e para o sujeito - e propõe a figura da interpelação do indivíduo em sujeito:

A modalidade particular do funcionamento da instância ideológica quanto à reprodução das relações de produção consiste no que se convencionou chamar interpelação, ou assujeitamento do sujeito como sujeito ideológico, de tal modo que cada um seja conduzido sem se dar conta, e tendo a impressão de estar exercendo sua livre vontade, a ocupar o seu lugar em uma ou outra das duas classes sociais antagonistas do modo de produção. (PÊCHEUX, 1997, p. 165-166)

Dessa forma, o autor deixa claro que, em seu arcabouço teórico, a articulação entre linguagem e ideologia é feita por intermédio do sujeito - sem o qual não há ideologia - em vez de ser feita por meio do signo. É importante aqui chamar atenção para um ponto importante do processo de assujeitamento: todas as palavras, as estruturas gramaticais, os sentidos e os próprios índices de valor disponíveis para o sujeito no momento da enunciação já foram criados e estabelecidos por outras pessoas e grupos. Apesar disso, o sujeito tem a impressão de que esta ou aquela frase, de que este ou aquele posicionamento axiológico seriam "próprios", "individuais", "autorais" ou frutos da sua "livre vontade". Essa impressão já é um efeito da ideologia, que Pêcheux (1997, p. 153) vai chamar de "efeito ideológico elementar".

Teríamos assim, de um lado, um sujeito bakhtiniano que, apesar de falar a 
partir de palavras que lhe foram dadas por outros sujeitos, é capaz de se apropriar delas de forma ativa e dialógica, concordando, rejeitando, alterando seu sentido e fazendo do signo a arena em que se dão os embates dos vários grupos que usam a língua. Já do lado pecheutiano, teríamos um sujeito assujeitado, cuja sensação de agência frente ao próprio dizer é uma ilusão, fruto de uma interpelação ideológica, uma vez que o processo de produção discursiva pecheutiano é concebido como "uma máquina autodeterminada [...], de tal modo que um sujeito-estrutura determina os sujeitos como produtores de seus discursos: os sujeitos acreditam que "utilizam" seus discursos quando na verdade são seus "servos" assujeitados, seus “suportes” (PÊCHEUX, 1997, p. 311).

Entre as obras de Bakhtin e de Ducrot, também escritas em contextos sociais e históricos muito distintos, há importantes aproximações e afastamentos. Uma aproximação seria o fato de Ducrot (1987) ter declaradamente utilizado elementos da teoria bakhtiniana como base para o seu "Esboço de uma teoria polifônica da enunciação". Um elemento importante é a existência de várias vozes, e não de um sujeito único e homogêneo, no polo da enunciação. Assim, enquanto Bakhtin estabelecia a distinção entre o autor-criador, o autor-pessoa, o herói, etc.,

Ducrot apontava vários locutores e os distinguia dos enunciadores. Essa distinção serve de base ao conceito de polifonia de ambos os autores. No entanto, enquanto a polifonia bakhtiniana seria utilizada de forma mais geral - por exemplo, para caracterizar a pluralidade de vozes coexistentes no romance de Dostoievski -, Ducrot trouxe seu conceito de polifonia para a pragmática linguística.

Ducrot também retoma outro importante conceito bakhtiniano: o de enunciado. Só que, desta vez, com diferenças muito mais profundas. A realização de um enunciado ducrotiano "é de fato um acontecimento histórico: é dada existência a alguma coisa que não existia antes de se falar e que não existirá mais depois. É essa aparição momentânea que chamo "enunciação"' (DUCROT, 1987, p. 168). É importante perceber que a historicidade aqui diz respeito ao posicionamento singular do enunciado no tempo e não à sua relação com os processos históricos. O enunciado ducrotiano é, por isso, momentâneo, evanescente, não havia antes da enunciação e não haverá depois, sendo radicalmente distinto do enunciado bakhtiniano que é "um elo na cadeia da comunicação verbal de uma dada esfera", "está repleto de ecos e lembranças dos outros enunciados, aos quais está vinculado" e "deve ser considerado, acima de tudo, uma resposta a outros enunciados anteriores dentro de uma dada esfera" (BAKHTIN, 2003c). Assim, essa concepção instantânea do enunciado ducrotiano termina por apagar uma ideia caríssima ao pensamento bakhtiniano: a de que as vozes que se tensionam nos enunciados refletem e refratam os tensionamentos históricos, sociais e ideológicos entre os vários grupos que se servem da língua.

A partir disso, é possível compreender mais claramente em que se baseiam afirmativas como as de que "as concepções de Bakhtin e de Ducrot de enunciado e polifonia são distintas, cobrindo diferentes formas de analisar as vozes do coro polifônico e recortes textuais distintos" (CATTELAN, 2008, p. 142); a de que na 
"retomada do conceito de polifonia, Ducrot exclui a noção de história, que, para Bakhtin, é uma noção fundamental" (BRANDÃO, 2005, p. 61) - ou mesmo o que opróprio Ducrot quis dizer com a expressão "bastante livre" ao afirmar, no "Esboço de uma teoria polifônica", que faria "uma extensão (bastante livre) à Linguística dos trabalhos de Bakhtin sobre a literatura” (DUCROT, 1987, p. 163).

Nessas linhas resumidas, esperamos ter mostrado que as divergências entre o pensamento de Bakhtin e o de Pêcheux dizem respeito a questões centrais, como a relação entre linguagem e ideologia e a agência do sujeito frente à linguagem; as divergências entre Bakhtin e Ducrot chegam ao ponto de conceitos centrais para ambas teorias serem bem distintos, como é o caso da polifonia ou mesmo falsos cognatos, como é o caso do conceito de enunciado. No que diz respeito ao objetivo deste artigo, chamamos particular atenção para o fato de que as diferenças entre as concepções de Bakhtin e Pêcheux sobre a relação entre sujeito, texto e sentido provocariam um afastamento epistemológico radical entre as duas teorias. Assim, entendemos que uma comparação mais detalhada entre a teoria bakhtiniana e as demais teorias que podem ser classificadas como análise do discurso revelaria divergências de igual monta.

Finalizamos esta seção respondendo à pergunta que guiou o texto até aqui. Por mais que, num primeiro momento, a teoria bakhtiniana e as teorias do discurso proponham uma articulação entre texto, sujeito, contexto, ideologia, linguagem, classes sociais, etc., as divergências que existem entre elas no nível da conceituação e da articulação entre os conceitos são por demasiado significativas. E é exatamente para marcar a existência dessas divergências que propomos que uma análise de textos a partir da teoria bakhtiniana seja chamada de análise bakhtiniana - em vez de análise do discurso.

\section{UM DISPOSITIVO PARA A ANÁLISE BAKHTINIANA}

Entendemos que a elaboração de um dispositivo para a análise bakhtiniana da linguagem deve estar firmemente ancorado em duas concepções exaustivamente reiteradas pelo autor (BAKHTIN, 2003a, 2003b, 2003c, 2006; VOLOSHINOV e BAKHTIN, 1976): a de que a análise dos fenômenos linguísticos deve ser feita nas condições concretas em que se realiza e a de que a real unidade da comunicação verbal e, consequentemente de sua análise, deve ser o enunciado, e não a palavra, a frase ou a oração.

Já do ponto de vista operacional, é importante estabelecer um critério para a identificação desses enunciados e um conjunto de procedimentos de análise. Abaixo esclarecemos todos os ponto para, por fim, apresentar o dispositivo analítico constituído a partir dessas definições. 


\section{Enunciado: características e identificação}

Conforme já foi abordado no início do presente trabalho, Bakhtin (2003c) constrói o conceito de enunciado a partir da comparação entre sua concepção de linguagem/comunicação e as concepções tradicionais à época. Assim, em vez das orações, palavras ou períodos extraídos do contexto em que ocorrem, chama atenção para os enunciados, tomando por base o diálogo cotidiano, face a face, em que se alternam as enunciações dos interlocutores.

O autor detalha as propriedades desse potente conceito, recorrendo insistentemente à comparação entre ele e a oração, numa espécie de contraponto entre o que pode e o que não pode ser considerado unidade de análise da comunicação verbal. Essa comparação é feita por intermédio de seis características apresentadas para o enunciado: estilo, construção composicional, unidade temática, relação com o falante/outros participantes, conclusibilidade e alternância dos sujeitos de fala. As três primeiras são características que os enunciados, unidades reais da comunicação, têm em comum com as orações, períodos e palavras - unidades convencionais da comunicação. Já as três últimas são características que diferenciam os enunciados das unidades linguísticas convencionais. Cabe destacar que essas características, apesar de tratadas individual e sequencialmente neste dispositivo, estão inarredavelmente imbricadas, dialogando e exercendo influência umas sobre as outras.

Se lembrarmos que nosso objetivo é estabelecer um critério para identificar um enunciado, podemos, de saída, descartar as três primeiras propriedades, no momento em que elas, por serem comuns a enunciados e orações, não se prestariam a distinguir aquelas destas.

Isso posto, teríamos, pelo menos em tese, três características que nos permitiriam diferenciar os enunciados, unidades reais, das orações, unidades convencionais: a relação com o falante/outros participantes, a conclusibilidade e alternância dos sujeitos de fala - que, não custa repetir, estão imbricadas entre si, com as outras e com o todo do enunciado. No entanto, uma leitura mais detalhada nos levou a optar pela última delas: a alternância dos sujeitos de fala.

$\mathrm{O}$ autor esclarece que "os limites da oração enquanto unidade da língua nunca são determinados pela alternância de sujeitos do discurso. Essa alternância, que emoldura a oração de ambos os lados, converte-a em um enunciado pleno" (BAKHTIN, 2003c, p. 277). Podemos também perceber a precisão que o autor atribui a esse critério de identificação do enunciado, quando considera que é "a alternância dos sujeitos do discurso, que emoldura o enunciado e cria para ele a massa firme, rigorosamente delimitada dos outros enunciados a ele vinculados" (BAKHTIN, 2003c, p. 279), ou quando descreve que "as enunciações (...) possuem, como unidades de comunicação discursiva, peculiaridades comuns e, antes de tudo, limites absolutamente precisos" (BAKHTIN, 2003c, p. 274). 


\section{0 ponto de partida}

Bakhtin (2006) propõe que a metodologia do estudo da língua deve seguir três etapas: “i) as formas e os tipos de interação verbal em ligação com as condições concretas em que se realiza; ii) as formas das distintas enunciações, dos atos de fala isolados, em ligação estreita com a interação de que constituem os elementos, isto é, as categorias de atos de fala na vida e na criação ideológica que se prestam a uma determinação pela interação verbal; iii) a partir daí, exame das formas da língua na sua interpretação linguística habitual" (p. 129). No restante do texto, assim como na maior parte de sua obra, não se dispõe a retomar nem detalhar essas etapas. É apenas em "Discurso na vida e discurso na arte: sobre a poética sociológica" (VOLOSHINOV e BAKHTIN, 1976) que podemos encontrar um exemplo de análise de enunciados, descrito na próxima seção, que, com um viés quase didático, complementa e detalha o estabelecido em Marxismo e filosofia da linguagem.

\section{Relação com 0 contexto}

$\mathrm{O}$ autor do ensaio "Discurso na vida e discurso na arte: sobre a poética sociológica", escrito em 1926, critica o método linguístico formal, em que toma-se o verbal não como um fenômeno sociológico mas de um ponto de vista abstrato, defendendo a importância do método sociológico para o estudo da poética, a partir de uma situação real.

A situação em questão refere-se a duas pessoas que estão sentadas numa sala, ambas em silêncio. Então, uma delas diz “Bem”. A outra não responde. O autor argumenta que para nós, que estamos ouvindo de fora, essa conversa apresenta-se completamente incompreensível. Porém, "esse colóquio peculiar de duas pessoas, consistindo numa única palavra - ainda que, certamente, pronunciada com entoação expressiva - faz pleno sentido, é completo e pleno de significação" (VOLOSHINOV e BAKHTIN, 1976, p. 5). Seu argumento baseia-se no fato de que por mais que se dê valor à parte verbal, com seus fatores fonéticos, morfológicos e semânticos da palavra do enunciado, ou seja, da palavra "bem”, não será possível dar um único passo para o entendimento do colóquio se não levarmos em consideração o contexto extraverbal, que era o seguinte: ambos os interlocutores olhavam para a janela e percebiam que começava a nevar, ambos sabiam que já se encontravam no mês de maio e que já era hora de chegar a primavera, e, finalmente, ambos estavam cansados do prolongado inverno e desapontados com a neve que ainda persistia em cair. Dessa forma, aponta o autor, a palavra "bem" se expandiria em alguma expressão metafórica tal como "que inverno teimoso, ele não vai parar, e Deus sabe que é hora” (VOLOSHINOV e BAKHTIN, 1976, p. 8).

Segundo o autor, o contexto extraverbal apresentado acima compreende três fatores: 1) o horizonte comum dos interlocutores (a unidade visível - nesse caso a sala, a janela, etc.), 2) o conhecimento e a compreensão comum da situação por parte dos interlocutores e 3) sua avaliação comum dessa situação. Cabe ressaltar que "comum" aqui não significa, necessariamente, concordância ou coinci- 
dência com o horizonte real, mas sim compartilhamento de determinada situação entre sujeitos participantes: "onde o campo de alcance é mais amplo, o enunciado pode agir apenas se sustentando em fatores constantes e estáveis da vida e em avaliações sociais substantivas e fundamentais" (VOLOSHINOV e BAKHTIN, 1976 , p. 6). Assim, diante do exposto, conclui o autor que "um enunciado concreto como um todo significativo compreende duas partes: (1) a parte percebida ou realizada em palavras e (2) a parte presumida. É nesse sentido que o enunciado concreto pode ser comparado ao entimema " "VOLOSHINOV e BAKHTIN, 1976, p. 6).

\section{Relações com a alteridade}

Ao fornecer um quadro dos fatores essenciais nas inter-relações dos participantes de um evento artístico, os autores de "Discurso na vida e discurso na arte: sobre a poética sociológica" afirmam que qualquer palavra, exceto a depositada num dicionário, é o produto da interação social de três participantes: o falante (autor), o interlocutor (leitor/ouvinte) e o tópico (o que ou quem) da fala (o herói). Ressalta, também, que autor, ouvinte e herói não são entidades fora da própria percepção da obra. Muito pelo contrário, são fatores constitutivos essenciais da obra. "Eles são a força viva que determina a forma e o estilo e são diretamente detectáveis por qualquer contemplador competente" (VOLOSHINOV e BAKHTIN, 1976, p. 13). Os autores também consideram que o ouvinte, em todos os casos, é entendido como o ouvinte que o próprio autor leva em conta, "aquele a quem a obra é orientada e que, por consequência, intrinsecamente determina a estrutura da obra" (p. 13) e que, portanto, de modo algum se refere às pessoas reais, em carne e osso, que de fato formam o público leitor do autor em questão. Assim como também não podemos nos referir ao autor - ou à imagem que fazemos do autor - como a pessoa de carne e osso que escreve.

Fica claro então que, para os autores, o que faz parte do meu enunciado, a quem eu me dirijo no elo da comunicação verbal, não é o destinatário, mas a imagem que faço dele. Essa imagem é inarredavelmente distinta do destinatário propriamente dito por uma série de motivos, a começar pela própria ontologia: enquanto a imagem que faço de uma pessoa quando enuncio é uma concepção, um pensamento, e, portanto, imaterial; a pessoa propriamente dita é de carne e osso, material, e, por isso, a ela seria impossível "entrar" num texto. Entendemos que o reconhecimento dessa alteridade, dessa clara diferenciação entre sujeitos "de texto" e sujeitos "de carne e osso" é um aspecto central do pensamento bakhtiniano e, por conseguinte, desse dispositivo.

Assim, por entender que a explicitação da alteridade entre sujeitos contribuirá decisivamente para a clareza do processo de análise, optamos pela seguinte nomenclatura: o ser humano que profere as palavras será chamado de autor-pessoa; o sujeito "de texto" responsável pelo todo estético da obra será chamado de autor-criador; aquilo de que se fala/ aquele sobre quem se fala/ aquele que fala no texto será chamado "herói" - em particular, o sujeito "de texto" que diz "eu" 
no texto será chamado de locutor; o sujeito "de texto" que corresponde à imagem que o autor-pessoa faz do destinatário será chamado "destinatário suposto", e o ser humano que de fato lerá as palavras será chamado de "destinatário real".

Antes de prosseguirmos, ressaltamos que a insistência no reconhecimento da alteridade entre sujeitos não implica que eles sejam completamente distintos e disjuntos em todas as situações. Entendemos que Bakhtin chama repetidamente a atenção para essa alteridade para deixar claro que esses sujeitos são de naturezas diferentes e, por isso, não podem coincidir integralmente. Tomando como exemplo o polo de enunciação, é perfeitamente possível que autor-pessoa, autor-criador e locutor estejam relacionados - e, no limite, até alinhados, como na frase "eu vou escrever um artigo". Mesmo nesse caso, o alinhamento não implica que esses sujeitos sejam idênticos, da mesma natureza. Ou, como quer o autor:

[...] em seu conjunto, o que acabamos de dizer não visa, absolutamente, a negar a possibilidade de comparar de modo cientificamente produtivo as biografias do autor e da personagem e suas visões de mundo, comparação eficiente tanto para a história da literatura quanto para a análise estética. Negamos apenas o enfoque sem nenhum princípio, puramente factual deste tema, que atualmente domina sozinho e se funda na confusão entre o autor-criador, elemento da obra, com o autor-pessoa, elemento do acontecimento ético e social da vida, e na incompreensão da relação do autor com a personagem. (BAKHTIN, 2003a, p. 9)

\section{Dispositivo analítico}

Articulando as etapas que destacamos de Marxismo e filosofia da linguagem, as propostas para análise de enunciados levadas a cabo em "Discurso na vida, discurso na arte ${ }^{2 "}$, o que destacamos acerca das relações de alteridade em torno do enunciado e o que destacamos sobre a plasticidade espacial e temporal das relações entre a parte realizada em palavras do enunciado e a parte presumida (contexto extraverbal), propomos um dispositivo que conste das seguintes etapas:

1. Identificação do enunciado. A partir das ideias apresentadas anteriormente, estabelecemos que a própria alternância entre os sujeitos falantes já é suficiente para identificar o enunciado, ou seja, o enunciado inicia-se no momento em que o falante toma a palavra para si e finaliza-se no momento em que este termina o que gostaria de dizer, permitindo que o outro também fale.

2. Leitura preliminar do enunciado. O objetivo desta etapa é estabelecer o primeiro contato com os enunciados propriamente ditos, identificando preliminarmente seus elementos linguísticos (léxico, sintaxe, estilo, construção composicional, unidade temática, relação com o falante/outros participantes, conclusibilidade) e procurando fazer uma articulação prévia entre o material linguístico, as questões de pesquisa e os conceitos bakhtinianos.

3. Descrição do contexto extraverbal. A partir da leitura preliminar e da articulação prévia das questões de pesquisa aos conceitos bakhtinianos, será realizada uma investigação do contexto extraverbal para identificar, dentre seus vários 
elementos, aqueles que mais contribuirão para a análise. Esses elementos serão então descritos e articulados com vistas a estabelecer o horizonte espacial comum dos interlocutores, seu conhecimento e compreensão da situação, sua avaliação comum dessa situação e o momento social e histórico em que ocorre. Essas informações descritas nesta etapa são coletadas anteriormente ao ato da enunciação.

4. Análise do enunciado. Consiste em articular os elementos linguísticos (léxico, sintaxe, estilo, construção composicional, unidade temática, relação com o falante/outros participantes), o contexto extraverbal e os conceitos bakhtinianos envolvidos para responder às questões de pesquisa.

Enquanto a primeira e a segunda etapa têm início, meio e fim bem-delimitados, a terceira etapa poderá ser revista e ampliada a qualquer momento da análise caso seja necessário buscar outros elementos do contexto extraverbal para melhor compreensão do enunciado. Essa possibilidade de recursão e de diálogo entre a terceira e a quarta etapa, que também permite articulação entre os elementos linguísticos, o contexto extraverbal e os conceitos bakhtinianos, confere plasticidade ao dispositivo, permitindo que sua aplicação seja realizada de forma não linear e conjuntamente à reflexão sobre as questões de pesquisa. Apresentamos na Figura 1 um diagrama para melhor compreensão do processo de análise do enunciado, de acordo com o dispositivo analítico proposto.

Figura 1: Etapas do dispositivo analítico proposto.



\section{O USO DO DISPOSITIVO ANALÍTICO PROPOSTO NO ENSINO DE CIÊNCIAS}

Esse dispositivo vem sendo utilizado como suporte teórico-metodológico para a produção de análises baktinianas de discursos no âmbito do ensino de Ciências. Recentemente têm sido produzidas análises de discursos para investigar perspectivas de professores sobre aspectos do ensino e para tentar delinear a construção discursiva da identidade docente de licenciandos. Esta 
seção traz resultados obtidos no âmbito de alguns desses estudos para dar uma ideia da contribuição do dispositivo analítico proposto.

Ferraz e Rezende (2014) investigaram as perspectivas sobre os Parâmetros Curriculares Nacionais do Ensino Médio (PCNEM) de professores de Física que participaram de um curso de extensão a distância sobre os objetivos do ensino de Ciências. Embora 39 professores tenham participado do curso, foram selecionados os enunciados de cinco professores de escolas públicas, sendo um de cada região do país. Julgamos que esse recorte proporcionaria a discussão e compreensão de como esses professores construíram suas perspectivas e revelaria possíveis relações com os diferentes contextos socioculturais em que estavam inseridos. Entretanto, apesar das diferenças regionais e individuais entre os cinco professores, foram observadas, em seus discursos, perspectivas semelhantes, de plena concordância com os PCNEM de Física. Ainda que tal aceitação possa estar ligada a certa imagem que os professores construíram do curso ou ao constrangimento para emitir críticas, na medida em que não foi possível investigar tais hipóteses, prosseguimos com a ideia de que possa ter havido de fato convergência na visão dos professores.

Como justificativa para a concordância com o que propõem as políticas curriculares, notou-se, em todos os enunciados, a defesa da metodologia da contextualização, proposta nos PCNEM de Física. Essa apropriação acrítica do ensino contextualizado está em sintonia com grande parte das pesquisas em ensino de Ciências, já que muitos dos trabalhos priorizam aspectos metodológicos e enaltecem o ensino contextualizado. Assim, tanto na literatura quanto na voz dos professores investigados, percebe-se que a contextualização das leis e fenômenos físicos é tratada como redentora de toda a sorte de problemas enfrentados no ensino de Física. Por outro lado, observamos que outras questões envolvidas nos PCNEM e no ensino de Física ficaram ausentes das perspectivas dos professores. A formação do cidadão e sua inserção na sociedade, os objetivos do atual currículo, sua relação com o mercado de trabalho, quem se pretende formar e o papel do professor enquanto intelectual transformador foram, por exemplo, tópicos silenciados nos enunciados analisados. Estes são apenas alguns exemplos de temas que poderiam trazer a perspectiva do professor para um viés mais crítico, privilegiando outros fatores que não a mera consideração do mundo vivencial do aluno na prática pedagógica. O silêncio em relação a esses temas molda a perspectiva dos professores e acentua a preocupação metodológica excessiva que visa meramente à transposição didática dos conteúdos exigidos pelo currículo, deixando de fora o questionamento sobre por que se tem este e não outro currículo.

Tendo como contexto o mesmo curso analisado por Ferraz e Rezende (2014), porém com o objetivo de analisar as perspectivas de 17 professores participantes sobre as relações entre o ensino de Física e o mercado de trabalho, Veneu (2012) constatou, já na etapa da leitura preliminar dos enunciados, que apenas cinco professores responderam à atividade na qual perguntava-se sobre a relação entre o ensino de Física e o mercado de trabalho, supondo uma resposta de 4.000 
caracteres. Ainda nessa etapa foi possível interpretar que a relação entre o ensino de Física e o mercado de trabalho, que tantointeressava ao pesquisador, não mobilizou esses professores a ponto deprovocar um posicionamento explícito. Assim, a imagem dos professores, feita pelo pesquisador, de que eles considerariam relevante discutir sobre a relação entre o ensino de Física e o mercado de trabalho não correspondeu aos destinatários reais, professores inscritos no curso. A análise do contexto extraverbal mais amplo levou à hipótese de que o silêncio dos professores poderia estar reverberando as políticas educacionais recentes, que ensejam a relação entre o ensino de Ciências e a preparação para o trabalho. Essa interpretação se mostrou compatível com a plena concordância dos mesmos sujeitos com as políticas curriculares, identificada no estudo de Ferraz e Rezende (2014).

A partir da análise de enunciados produzidos no contexto de uma entrevista semiestruturada com um licenciando, Costa e Rezende (2014) constataram que sua escolha pelo curso a distância de licenciatura em Ciências Biológicas se deveu à possibilidade que essa modalidade de ensino lhe proporcionara de manter sua atividade profissional de extensionista rural, e que seu real interesse seria, de fato, um curso na área das Ciências Agrárias. De maneira geral, sua perspectiva e enunciados foram marcados por sua identidade ruralista, moldando a construção discursiva de sua identidade docente e caracterizando-a por hibridismo, pois embora tivesse deixado claro que sua aptidão e referência de formação eram aquelas relacionadas à sua atividade profissional agrária, a licenciatura em Ciências Biológicas veio a somar com sua identidade anterior, inclusive quando considerou que as habilidades didáticas aprendidas no curso estavam auxiliando em seu desempenho profissional atual. Dessa maneira, a análise contribuiu para a compreensão de que seu contexto sociocultural permeou todo o seu discurso, mesclando-se completamente à construção de uma possível identidade docente. As autoras concluíram que estudos como esse, que buscam ouvir os estudantes para compreender o fenômeno formativo, sempre complexo, são capazes de mostrar como representações e referências anteriores concorrem com discursos produzidos ao longo da formação para forjar a identidade profissional.

O estudo de Beja e Rezende (2014) teve como objetivo investigar processos de construção discursiva da identidade docente vivenciados por quatro estudantes de um curso de licenciatura em Química. O corpus analisado foi constituído por narrativas produzidas pelas licenciandas em dois momentos da trajetória formativa. $\mathrm{O}$ estudo teve como base teórica aportes que concebem a construção da identidade - e, por conseguinte, da identidade docente - na e pela linguagem, nas interações com o outro, de forma relacional e sempre motivada pela diferença. Com essa abordagem, foi possível desvendar nos enunciados de Marie e de Irene, o diálogo com conhecimentos teóricos presentes no curso de licenciatura e a identificação do professor com o papel de mediador; e nos enunciados de Ada e de Dorothy, o diálogo com valores e representações sociais formados desde a infância, nas experiências escolares, que identificam o professor com o papel de guia e de missionário.A análise dos processos vivenciados por Ada e Dorothy revelaram 
- muito mais do que aqueles vivenciados por Marie e Irene - o quanto modelos anteriores ao curso podem resistir ao processo de formação e pouco interagir com eles. A permanência de representações que dialogam com modelos externos ao curso indica como os valores e as representações formados desde a infância nas experiências escolares precisam ser assumidos como componentes significativos da identidade docente e considerados igualmente como alvo do processo formativo.

\section{DISCUSSÃO, CONSIDERAÇÕES FINAIS E IMPLICAC̣ÕES PARA A PESQUISA EM EN- SINO DE CIÊNCIAS}

O dispositivo analítico ora proposto pode ser usado com total flexibilidade, subsidiando a análise de discursos originados nos mais diversos contextos socioculturais. Nesse sentido, acreditamos termos conseguido avançar em relação a outros dispositivos que se baseiam no suporte teórico bakhtiniano, como, por exemplo, em relação à ferramenta analítica proposta por Mortimer e Scott (2002), que se restringe ao objetivo de "analisar maneiras através das quais professores interagem com alunos para promover a construção do significado no plano social das aulas de Ciências na escola secundária” (p. 283). Também consideramos ter avançado por termos elegido o enunciado como unidade de análise, por entendermos ser essa unidade a que Bakhtin defende em todos os seus textos, e não outra unidade que não se equipara teoricamente ao de enunciado, como, por exemplo, o "episódio", utilizada por Mortimer e Scott (2002).

Entendemos que o arcabouço teórico criado por Bakhtin tem elementos mais do que suficientes para dar suporte a apropriações que pretendam ir além do uso pontual deste ou daquele conceito. Entendemos, também, que o referencial sustenta a elaboração de um dispositivo cuja unidade de análise é o enunciado, perfeitamente identificado pela alternância de sujeitos falantes. A interpretação do enunciado deve ser feita na sua relação com as três escalas de tempo, contexto e interlocução, com particular atenção para as alteridades entre sujeitos empíricos e sujeitos de texto e para a parte presumida do enunciado. $\mathrm{O}$ arcabouço bakhtiniano permite ainda delinear um posicionamento epistemológico do pesquisador, a partir da natureza axiológica e valorativa do enunciado, da ideia (trazida por Bakhtin da mecânica quântica) de que o observador interfere no que é observado e, ainda, da concepção de que o objeto das ciências humanas é o encontro entre a consciência do pesquisador e a do pesquisado. Esse posicionamento coloca em xeque tanto a neutralidade do pesquisador quanto o conhecimento da coisa em si. Se de fato só for possível conhecer a coisa para si - e ainda de forma axiológica - enunciados com léxico e sintaxe mais taxativos, como, por exemplo, "o professor é construtivista" não seria encarado pelo leitor bakhtiniano como fato, mas sim como uma perspectiva sobre a prática do professor.

Ainda comparando a análise de conteúdo com a análise bakhtiniana, des- 
tacamos uma importante mudança no papel do contexto na análise do enunciado. Enquanto na análise de conteúdo o contexto apenas auxiliaria na compreensão deste ou daquele dado linguístico, na análise bakhtinina o contexto é constitutivo dos enunciados e, portanto, imprescindível a qualquer análise.

Uma análise do texto com base na teoria de Pêcheux muito certamente teria sua concepção de sentido bem afastada da concepção da análise de conteúdo - em que o sentido está escondido no texto - e bem próxima daquela da análise bakhtiniana, pois "o sentido de uma palavra, expressão, proposição, não existe em si mesmo (isto é, em sua relação transparente com a literalidade do significante), mas é determinado pelas posições ideológicas colocadas em jogo no processo sociohistórico em que palavras, expressões, proposições são produzidas" (PÊCHEUX, 1997, p. 160). Porém, essas marcas são consideradas interpelação, e não posições do sujeito.

Para tratar de outro ponto importante destas considerações finais, retomamos o levantamento do início do trabalho: dentre os 66 artigos que usavam a palavra discurso para qualificar o objeto de pesquisa, $42 \%$ não faziam qualquer alusão a um referencial teórico da área de linguagem ou simplesmente faziam referência, mas não detalhavam a concepção de linguagem do artigo, e 58\% detalhavam as concepções de linguagem para análise do discurso utilizadas, usando, por vezes, mais de um autor para atingir esse fim.

Quanto ao primeiro grupo, entendemos que essa falta de filiação ou de detalhamento teórico pode se dever ao fato de os autores desses trabalhos, em sua maioria originários das áreas de ciências naturais, terem tratado o texto, o contexto, o sujeito e o sentido como objetos estanques e de sentido unívoco, cuja definição é compartilhada tacitamente por todos os outros pesquisadores - bem à guisa dos objetos das ciências naturais. $\mathrm{O}$ arcabouço bakhtiniano é pleno em subsídios para a abordagem dessa questão, chegando a tratar diretamente do assunto em "Metodologia das ciências humanas" (BAKHTIN, 2003a) e em "O problema do texto na linguística, filologia e outras ciências humanas” (BAKHTIN, 2003b).

No que diz respeito ao segundo grupo, entendemos que os autores trataram o texto analisado como um objeto de pesquisa das ciências humanas, estabelecendo as relações entre texto, contexto, sentido, etc. de acordo com os teóricos escolhidos. No entanto, no que tange à articulação de diferentes teóricos da área da linguagem, algo bastante comum nesse grupo, esperamos ter mostrado o quão divergentes - e, no limite, incompatíveis - podem ser as diversas teorias acerca dos fenômenos linguísticos.

No entanto, nenhum dos 66 trabalhos encontrados toca numa questão que julgamos central para a investigação sobre dados de linguagem na pesquisa: da mesma maneira que o sujeito de pesquisa produz um texto sobre um determinado objeto, o pesquisador, ao investigar o texto produzido, também é um sujeito produzindo um texto sobre um determinado objeto. Assim, entendemos que é importante que o referencial teórico escolhido para analisar a fala do pesquisado seja estendido à análise realizada pelo próprio pesquisador, a quem caberia discutir 
as implicações epistemológicas do uso desse referencial teórico para a pesquisa. Frisamos aqui que, com a apresentação das várias diferenças entre a análise bakhtiniana, a análise de conteúdo e a análise do discurso, não pretendemos sugerir a substituição de um caminho pelo outro. Queríamos, sim, contribuir para que os pesquisadores da área escolham o caminho que mais se adeque à leitura que fazem do problema que investigam, conhecendo, também, os ônus e bônus epistemológicos em assumir uma filiação.

Ao empreender uma análise do conteúdo, por exemplo, o pesquisador usa rigor metodológico para evitar que sua subjetividade interfira na análise, garantindo, assim, seu afastamento do objeto. Dessa maneira, poderá legitimar o sentido encontrado, entendido como único, coisa em si. Esse sentido único legitimado nos remete à ideia de reprodutibilidade e fidedignidade, aproximando a análise do conteúdo do positivismo. Se tomássemos como exemplo os jornais e a propaganda de guerra sobre as quais a análise de conteúdo se debruçou no início de sua história, a análise de conteúdo permitiria descobrir - e, no limite, provar - que um determinado periódico fazia circular a ideologia comunista ou não, independente do posicionamento ideológico do analista.

Já na análise bakhtiniana, a interação entre sujeito e objeto (os outros sujeitos) não é vista como algo a se eliminar, mas como constitutiva da análise. O rigor metodológico, nesse caso, seria justamente reconhecer esse fato, identificar e problematizar essas marcas. Isso, no entanto, minimiza a possibilidade de reprodutibilidade e fidedignidade. Analistas diferentes, por terem perspectivas diferentes, farão análises diferentes. O sentido deixa de ser único e da ordem da coisa em si, para ser plural e da ordem da coisa para si. Assim como já destacamos anteriormente, não se tratata de um "vale-tudo", em que qualquer sentido é válido, pois o sujeito em Bakhtin é um sujeito social, que interage com seu contexto extraverbal e com seus interlocutores e cujo enunciado está profundamente marcado por essas interações.

No caso da análise da propaganda de guerra, teríamos que problematizar o resultado das análises bakhtinianas - que, não custa repetir, poderiam ter resultados distintos ou até mesmo divergentes - em função das concepções políticas com as quais os analistas se identificam. O posicionamento de cada um deveria ser explicitado para que o leitor pudesse fazer seu próprio julgamento. Mas o que se ganha e o que se perde com isso?

No caso da análise de conteúdo, a filiação ao positivismo conduziria qualquer analista a uma mesma verdade e permitiria provar que este ou aquele sentido é o verdadeiro. Por outro lado, a existência de sentido verdadeiro obtido mediante prova não permitiria acessar a complexidade das relações sociais e históricas em que se inserem sujeito e objeto. Já a análise bakhtiniana atingiria a complexidade dessas relações sociais e históricas, bem como as múltiplas dimensões e perspectivas acerca do objeto. Esse conhecimento, no entanto, teria uma consequência epistemológica bastante expressiva: a impossibilidade de acessar um sentido verdadeiro. Assim, o bônus de conhecer a verdade e poder provar sua existência teria 
como ônus a desconsideração à multiplicidade e complexidade dos objetos sociais e históricos. E, inversamente, o ônus da impossibilidade de conhecer e provar a existência de um sentido verdadeiro teria o bônus de acessar a complexidade do objeto investigado. Discussão análoga, mas com desdobramentos muito distintos, poderia ser realizada, por exemplo, acerca da escolha entre a análise do discurso de linha francesa, com suas formações discursivas e seus sujeitos assujeitados e a análise bakhtiniana, com seus sujeitos dialógicos lutando pelo sentido na arena dos signos.

Essas discussões epistemológicas, por evidenciarem diferenças radicais entre os objetos das ciências humanas e naturais, são particularmente importantes para os pesquisadores da área de ensino de Ciências que, na maior parte das vezes, articulam formação básica em ciências naturais e formação em ciências humanas. Primeiramente porque, por mais que seja possível fazer uma diferenciação entre o saber do pesquisador e o saber escolar, o ensino das ciências naturais precisa de um mínimo de adesão epistemológica à concepção que os pesquisadores fazem dessa ciência natural. Seria importante, portanto, explicitar e discutir sua filiação a essa concepção de objeto de pesquisa. Por outro lado, o objeto da pesquisa em educação é, certamente, o objeto das ciências humanas e, para fazer sua adesão à área de pesquisa em educação, o ensino de Ciências precisaria também reconhecer/discutir sua filiação a essa concepção de objeto de pesquisa, o que pode gerar sérias divergências epistemológicas.

Assim, enquanto pesquisadores de ensino de ciências humanas poderiam fazer a adesão à área de pesquisa daquela ciência humana sem dar maior atenção a essas diferenciações, os pesquisadores da área de ensino de Ciências estariam numa posição desafiadora, justamente porque a filiação simultânea à área de pesquisa em ciências naturais e à área de educação pode implicar mudanças radicais na concepção de objeto de pesquisa. Por outro lado, essa dupla formação também pode ser potencializada de modo a se configurar como uma posição privilegiada para discutir as diferenças entre os objetos das ciências humanas e os das naturais.

Em relação à análise de discursos, tratada neste trabalho, entendemos que mesmo uma escolha epistemológica considerada mais próxima à pesquisa em ciências naturais, no caso, a opção pela análise de conteúdo, requer maior clareza sobre essa filiação epistemológica e uso mais consciente e consequente desse tipo de análise. Se a opção for por tratar o texto como um objeto de pesquisa das ciências humanas, a partir da filosofia da linguagem de Bakhtin, precisaríamos também abordar com clareza aquilo que se ganha e aquilo que se perde em termos epistemológicos: afinal, não há bônus sem ônus - e vice-versa.

\section{NOTA:}

${ }^{1} \mathrm{O}$ entinema é uma forma de silogismo em que uma das premissas não é expressa, mas presumida. Por exemplo: Sócrates é um homem, portanto é mortal”. A premissa presumida seria "Todos os homens são mortais". 
2 Nessas propostas, o enunciado como um todo teria duas partes: uma presumida e a outra realizada em palavras. Na parte presumida, faremos a análise 1) do horizonte espacial comum dos interlocutores (a unidade do visível - nesse caso, a sala, a janela, etc.), 2) do conhecimento e compreensão comum da situação por parte dos interlocutores e 3) de sua avaliação comum dessa situação.

Informações sobre a participação dos autores na elaboração deste artigo:

Aroaldo Veneu e Gleice Ferraz: elaborações teóricas e metodológicas relacionadas às suas dissertações de mestrado.

Flavia Rezende: orientadora das dissertações de mestrado de Aroaldo Veneu e Gleice Ferraz e coordenadora da elaboração do artigo.

\section{REFERÊNCIAS}

ALMEIDA, M. J. P. M. Discursos da ciência e da escola: ideologia e leituras possíveis. Campinas: Mercado de Letras, 2004.

BARDIN, L. (1995). Análise de Conteúdo. Lisboa: Edições 70, 1995.

BAKHTIN, M. Metodologia das ciências humanas. In: . Estética da criação verbal. Tradução de Paulo Bezerra. 4a ed. São Paulo: Martins Fontes, p. 393-410, 2003a.

. O problema do texto na linguística, filologia e outras ciências humanas. In: Estética da criação verbal. Tradução de Paulo Bezerra. 4a ed. São Paulo: Martins Fontes, p. 307-335, 2003 b. . Os gêneros do discurso. In: Estética da criação verbal. Tradução de Paulo Bezerra. 4. ed. São Paulo: Martins Fontes, p. 261-306, 2003c. . Marxismo e filosofia da linguagem. 12 ed., São Paulo: Hucitec, 2006.

BEJA, A. C. S.; REZENDE. Processos de construção da identidade docente no discurso de estudantes da licenciatura em Química.Revista Electrónica de Enseñanza de las Ciencias, Vigo, v. 13, n. 2, p. 156-178, 2014.

BRANDÃO, H. N. Introdução à análise do discurso. Campinas: Unicamp, 2005.

CATTELAN, J. C. Colcha de retalhos: micro-história e subjetividade. Cascavel: Edunioeste, 2008.

COSTA, M. L. R.; REZENDE, F. Cosntrução da identidade docente de um estudante de licenciatura em ciências biológicas em curso a distância: um caso de hibridismo. Revista Ensaio-Pesquisa em educação em Ciências, Belo Horizonte, v.16, n.1, p. 149-169, 2014.

DUCROT, O. O dizer e o dito. Campinas, SP: Pontes, 1987.

FERRAZ, G.; REZENDE, F. Perspectivas de professores de Física sobre as políticas curriculares nacionais para o ensino médio. Ciência \& Educação, Bauru, v. 20, n. 2, p. 497-515, 2014.

GILL, R. Análise de Discurso. In: Bauer M. W., Gaskell G. Pesquisa qualitativa com texto, imagem e som: um manual prático. 3a ed. Petrópolis (RJ): Vozes, p. 244-270, 2002.

MARTINS, I. Quando o objeto de investigação é o texto: uma discussão sobre as contribuições da Análise Crítica do Discurso e da Análise Multimodal como referenciais para a pesquisa sobre livros didáticos de Ciências. In: NARDI, R. (Org.). A pesquisa em Educação em Ciências no Brasil: alguns recortes. 1ed. São Paulo: Escrituras, 2007. p. 95-116.

MORTIMER, E. F.; SCOT'T, P. Atividade discursiva nas salas de aula de Ciências: uma ferramenta sociocultural para analisar e planejar o ensino. Investigações em Ensino de Ciências, Porto Alegre, v.7, n.3. Disponível em: <http://www.if.ufrgs.br/public/ensino/

revista.htm>. Acesso em: 10 jul. 2014.

PECHEUX. M. A Análise do Discurso: Três Épocas. (Trad. de J. de A. Romualdo). In: GADET, F. \& HAK, T. (Orgs.) Por uma análise automática do discurso: uma introdução à obra de Michel Pêcheux. Campinas: Editora da Unicamp, 1997. p. 311-318. 
ROCHA, D.; DEUSDARÁ, B. Análise de conteúdo e análise do discurso: o linguístico e seu entorno. DELTA, São Paulo, v. 22, n. 01, p. 29-52, 2006.

VENEU, A. A. Perspectivas de professores de Física do Ensino Médio sobre a relação entre o ensino de Física e o mercado de trabalho: uma análise bakhtiniana. 2012. 253 f. Dissertação (Mestrado em Educação em Ciências e Saúde) - Núcleo de Tecnologia Educacional para a Saúde (Nutes), Universidade Federal do Rio de Janeiro, Rio de Janeiro, RJ, 2012.

VOLOSHINOV, V. N.; BAKHTIN, M. Discurso na vida e discurso na arte. Trad. Cristóvão Tezza e Carlos A. Faraco. (Texto de circulação acadêmica), 1976.

Data de Recebimento: 12/08/2013

Data de Aprovação: 07/07/2014

Data da Versão Final: 16/07/2014

\section{Contato:}

Aroaldo Veneu

NUTES-UFRJ, CCS, Bloco L, Laboratório de Tecnologias Cognitivas

Ilha do Fundão, Rio de Janeiro - RJ - CEP: 21945-900 - Brasil

Email: aroaldo@gmail.com 